\title{
Preliminary tests of silicon carbide based concretes for hybrid rocket nozzles in a solar furnace ${ }^{2 / 3}$
}

\author{
Raffaele D'Elia $^{\mathrm{a}, \mathrm{b}, *}$, Gérard Bernhart ${ }^{\mathrm{b}}$, Thierry Cutard $^{\mathrm{b}}$, Gilles Peraudeau ${ }^{\mathrm{c}}$,
}

Marianne Balat-Pichelin ${ }^{c}$

\author{
${ }^{a}$ CNES - Direction des Lanceurs, 52 rue Jacques Hillairet, 75612 Paris Cedex, France \\ ${ }^{\mathrm{b}}$ Université de Toulouse, Mines Albi, INSA, UPS, ISAE, ICA; Campus Jarlard, F-81013 Albi cedex 09, France \\ ${ }^{\mathrm{c}}$ PROMES-CNRS, 7 rue du four solaire, 66120 Font-Romeu Odeillo, France
}

\section{Keywords:}

Silicon carbide

Refractory concrete

Active oxidation

Nozzle materials

Solar furnace

Thermo-mechanical testing

\section{A B S T R A C T}

This research is part of the PERSEUS project, a space program concerning hybrid propulsion and supported by CNES. The main goal of this study is to characterise silicon carbide based micro-concrete with a maximum aggregates size of $800 \mu \mathrm{m}$, in a hybrid propulsion environment. The nozzle throat has to resist to a highly oxidising polyethylene $(\mathrm{PE}) / \mathrm{N}_{2} \mathrm{O}$ hybrid environment, under temperatures ranging up to $2980 \mathrm{~K}$.

The study is divided into two main parts: the first one deals with the thermo-mechanical characterisation of the material up to $1500 \mathrm{~K}$ and the second one with an investigation on the oxidation behaviour in a standard atmosphere, under a solar flux up to $13.5 \mathrm{MW} / \mathrm{m}^{2}$.

Young's modulus was determined by resonant frequency method: results show an increase with the stabilisation temperature. Four point bending tests have shown a rupture tensile strength increasing with stabilisation temperature, up to $1473 \mathrm{~K}$. Sintering and densification processes are primary causes of this phenomenon. Visco-plastic behaviour appears at $1373 \mathrm{~K}$, due to the formation of liquid phases in cement ternary system.

High-temperature oxidation in ambient air was carried out at PROMES-CNRS laboratory, on a $2 \mathrm{~kW}$ solar furnace, with a concentration factor of 15,000 . A maximum $13.5 \mathrm{MW} / \mathrm{m}^{2}$ incident solar flux and a 7-90 s exposure times have been chosen. Optical microscopy, SEM, EDS analyses were used to determine the microstructure evolution and the mass loss kinetics. During these tests, silicon carbide undergoes active oxidation with production of $\mathrm{SiO}$ and $\mathrm{CO}$ smokes and ablation. A linear relation between mass loss and time is found. Oxidation tests performed at $13.5 \mathrm{MW} / \mathrm{m}^{2}$ solar flux have shown a mass loss of $10 \mathrm{mg} / \mathrm{cm}^{2}$ after $15 \mathrm{~s}$. After $90 \mathrm{~s}$, the mass loss reaches $60 \mathrm{mg} / \mathrm{cm}^{2}$.

Surface temperature measurement is a main point in this study, because of necessity of a thermo-mechanical-ablative model for the material. Smokes appear at around $5.9 \mathrm{MW} / \mathrm{m}^{2}$, leading to the impossibility of useful temperature measurements by optical pyrometry.

Micro-concrete is really interesting for the nozzle realisation, thanks to its workability, and its thermo-mechanical properties. After $30 \mathrm{~s}$, mass loss in micro-concrete is one half of pure $\alpha$-SiC. This result is really interesting to study SiC-based concretes in oxidising environments, instead of sintered $\alpha-\mathrm{SiC}$.

\footnotetext{
This article was presented during the 64th IAC in Beijing.

* Corresponding author at: Université de Toulouse; Mines Albi, INSA, UPS, ISAE, ICA; Campus Jarlard, F-81013 Albi cedex 09, France. Tel.: +337 782012 40; fax: +33563493242.

E-mail addresses: raffaele.delia176@gmail.com, infinito176@hotmail.it (R. D'Elia).
} 


\section{Introduction}

SiC-based ceramics are very interesting materials for high temperature space applications, because of $\mathrm{SiO}_{2}$ scale formed in passive oxidation conditions, with a parabolic mass gain. The reaction that occurs is the following:

$\mathrm{SiC}(s)+(3 / 2) \mathrm{O}_{2}(g)=\mathrm{SiO}_{2}(s)+\mathrm{CO}(g)$

However when oxygen partial pressure is lower than the stability value [1], that depends on temperature, the SiC substrate undergoes rapid active oxidation, with formation of gaseous products and linear mass loss [2]. The stability value characterises the passive-to-active transition of the material and it will be discussed later in this paper for our material.

The reaction in this domain is the following:

$$
\mathrm{SiC}(s)+\mathrm{O}_{2}(g)=\mathrm{SiO}(g)+\mathrm{CO}(g)
$$

At $1613 \mathrm{~K}$ calcium aluminate cement [3], that binds SiC aggregates in concrete, forms a fluid vitreous phase in the $\mathrm{CaO}-\mathrm{Al}_{2} \mathrm{O}_{3}-\mathrm{SiO}_{2}$ (CAS) ternary system [4]. In real systems, cement sulphates and carbonates together have low melting point eutectics, of the order of $1073-1173 \mathrm{~K}$ [3]: this transient melting is quantitatively ephemeral, but it is important for cement sintering and densification. When cement eutectics appear, the liquid quantity abruptly rises from zero to a significant value, in the range of $15-25 \%$ [3]. These phases allow concrete densification and ceramization, reducing the open porosity and increasing the thermo-mechanical properties.

The aim of this study, part of the PERSEUS project, launched by CNES in 2006, is to characterise a particular SiC-based refractory concrete in a hybrid propulsion environment and to finally manufacture a complete nozzle, for tests at ONERA, France.

Concrete will be exposed to a very oxidising environment. According to ONERA data, a chamber pressure of 1.7 MPa, a contraction area ratio of 12.6 and an expansion area ratio of 4 have been used to calculate nozzle throat conditions with the Rocket Propulsion Analysis (RPA) software. Calculations have been made by optimising mixture ratio $(\mathrm{O} / \mathrm{F})$. The optimum value is 7.65 (Fig. 1).

A throat pressure of $0.98 \mathrm{MPa}$ is obtained, with temperature levels up to $2980 \mathrm{~K}$. Combustion time is $20 \mathrm{~s}$. Exhaust gases produced by polyethylene (PE) $/ \mathrm{N}_{2} \mathrm{O}$ hybrid rocket contain more oxidising chemical species than VEGA's P80 solid booster ${ }^{1}$ : $9.8 \mathrm{~mol} \% \mathrm{CO}_{2}$ (against $1.2 \mathrm{~mol} \%$ ), $17.7 \mathrm{~mol} \% \mathrm{H}_{2} \mathrm{O}$ (against $11.8 \mathrm{~mol} \%$ ) and $0.6 \mathrm{~mol} \% \mathrm{O}_{2}$ (against $0.0 \mathrm{~mol} \%)$.

From here the idea is to use SiC-based refractory concrete, which is less reactive than graphite used in other similar CNES projects. Moreover concrete processing route is really simple, and it allows the nozzle manufacturing in only one piece.

${ }^{1}$ VEGA (Vettore Europeo di Generazione Avanzata) is an expendable launch system in use by Arianespace, jointly developed by ASI and ESA. P80 is its first stage, a solid rocket motor based on a propellant (Hydroxyl-terminated polybutadiene 1912) with low binder content and high aluminium percentage [27].

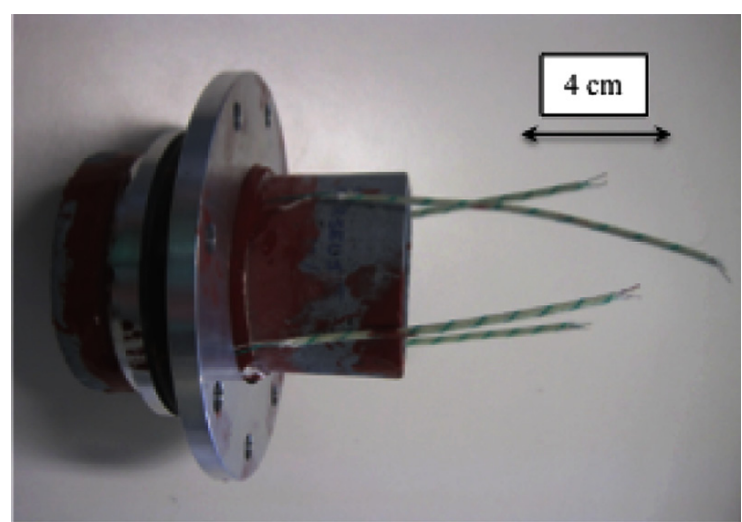

Fig. 1. PERSEUS nozzle in refractory concrete, with silica insulating material, aluminium carter and four K-type thermocouples.

To save time and resources in the product development, relatively simple approaches should be tried, like the use of concrete type materials. Its utilisation is an attractive alternative. Compared to metallic materials, a cooling system is not necessary, because of different types of heat dispersion: smoke generation, liquid phases formation, vaporisation and oxidation.

Ablation heat quantifies all these phenomena. Our purpose is to understand ablation, oxidation of concrete and to measure mass loss as a function of time.

The approach used in this paper is to perform a preliminary investigation in a solar furnace, under a standard atmosphere. This study will allow a first comprehension of material oxidation. It will be the starting point for the understanding of future experiments using a hybrid rocket motor (HRM).

\section{Materials and methods}

\subsection{Concrete processing route}

Refractory concretes are unshaped materials. To ensure binding between the aggregates, cement has to follow a processing route to allow hydraulic bond formation. The chemical composition of the concrete used in this study is shown in Table 1.

The studied concrete is composed of a calcium aluminate cement, which contains almost $70 \mathrm{wt} \%$ of alumina. SiC is the main component, with a maximum aggregates size of $800 \mu \mathrm{m}$. This aggregates size is not common in concrete; for this reason this material has been renamed microconcrete (MC).

The hydraulic bond is formed when mixing water is added to cement. Water quantity is calculated to ensure perfect equivalence with reactive phases in cement: $C_{3} A^{2}$, $C_{12} A_{7}, C A, C A_{2}, C A_{6}$. Each phase has a different reactivity with water to form hydrates, which depends upon $\mathrm{C} / \mathrm{A}$ ratio. In particular the first two phases $\left(C_{3} A\right.$ and $\left.C_{12} A_{7}\right)$ dissolve immediately in water, while the three others ( $C A$, $\mathrm{CA}_{2}, \mathrm{CA}_{6}$ ) are more stable [4].

\footnotetext{
${ }^{2} \mathrm{C}=\mathrm{CaO}, \mathrm{A}=\mathrm{Al}_{2} \mathrm{O}_{3}$.
} 
Table 1

Chemical composition of MC [5].

\begin{tabular}{llll}
\hline $\begin{array}{l}\text { Chemical } \\
\text { species }\end{array}$ & $\begin{array}{l}\text { Average } \\
\text { composition }\end{array}$ & $\begin{array}{l}80-800 \mu \mathrm{m} \\
(60 \mathrm{wt} \%)\end{array}$ & $\begin{array}{l}<80 \mu \mathrm{m} \\
(40 \mathrm{wt} \%)\end{array}$ \\
\hline $\mathrm{SiC}$ & $80.0 \mathrm{wt} \%$ & $100 \mathrm{wt} \%$ & $50.0 \mathrm{wt} \%$ \\
$\mathrm{Al}_{2} \mathrm{O}_{3}$ & $14.0 \mathrm{wt} \%$ & - & $34.0 \mathrm{wt} \%$ \\
$\mathrm{SiO}_{2}$ & $5.0 \mathrm{wt} \%$ & - & $13.0 \mathrm{wt} \%$ \\
$\mathrm{CaO}$ & $1.4 \mathrm{wt} \%$ & - & $3.5 \mathrm{wt} \%$ \\
\hline
\end{tabular}

MC requires $8.3 \mathrm{wt} \%$ of water, that is mixed with concrete during $6 \mathrm{~min}$. Then, concrete is poured in $25 \times 25 \times$ $150 \mathrm{~mm}^{3}$ mould, locked on a vibrating table to reduce concrete porosity. Concrete is then stabilized under plastic film during $48 \mathrm{~h}$ at $293 \mathrm{~K}$, to ensure correct hydration. Plastic film prevents different evaporation between the top and the core of the sample. Concrete is then placed in oven at $383 \mathrm{~K}$ during $24 \mathrm{~h}$, to ensure complete water evaporation. Finally samples are fired at $1473 \mathrm{~K}$ during $5 \mathrm{~h}$. Temperature ramp is really important, because of spalling or explosions phenomena if it is too fast. Normal temperature ramp is $100 \mathrm{~K} / \mathrm{h}$ [6]. After cooling, samples are cut with diamond saw. Fig. 2 shows a sample before test.

\subsection{Concrete properties}

According to triple weighing measurement [7], material density is $2580 \mathrm{~kg} / \mathrm{m}^{3}$, with an open porosity of $17.06 \mathrm{vol} \%$. Nominal open porosity at $1073 \mathrm{~K}$ is $21 \mathrm{vol} \%$ [5]. This important difference is linked to the liquid phases produced between $1073 \mathrm{~K}$ and $1473 \mathrm{~K}$, with cement sintering and the associated densification [6].

Specific heat capacity as a function of temperature has been calculated by the rule of mixture. Results are shown in Fig. 3.

According to calculation results, MC and silicon carbide have the same specific heat capacity. All the curves have been calculated using Shomate equations, from the NIST tables [8-11]. Experimental curves agree with calculation results.

Thermal diffusivity of MC is shown in Fig. 4. It was measured by Laser Flash Analysis (LFA) up to $725 \mathrm{~K}$. According to experimental results, this quantity follows a power law. The exponent is -0.87 and the coefficient of determination $R^{2}$ is 0.95 .

An extrapolation shows a value of $1.6 \mathrm{~mm} / \mathrm{s}^{2}$ at $2000 \mathrm{~K}$. A similar behaviour can be found in [12] for the thermal conductivity of high-purity silicon carbide. Results are shown in Table 2.

Thermal conductivity of MC calculated from the results of Figs. 3 and 4 is shown in Fig. 5.

A thermal conductivity of $12.8 \mathrm{~W} / \mathrm{mK}$ at $290 \mathrm{~K}$ has also been measured by Hot Disk method. According to the curve of Fig. 5, a thermal conductivity of $14.8 \mathrm{~W} / \mathrm{mK}$ is found at this temperature, which agrees with the experimental value.

Fig. 6 shows concrete microstructure: $\mathrm{SiC}$ aggregates are light grey and irregular, surrounded by the cement

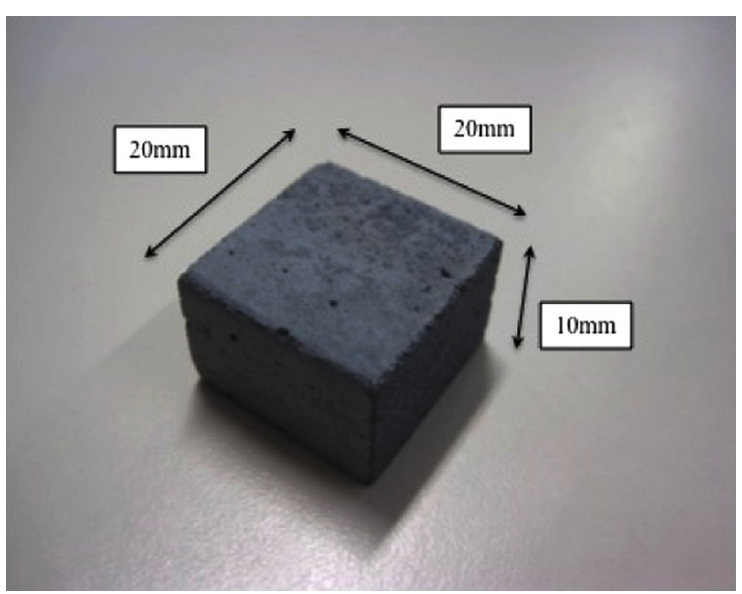

Fig. 2. MC sample used in solar furnace tests. Dimensions are $20 \times 20 \times 10 \mathrm{~mm}^{3}$.

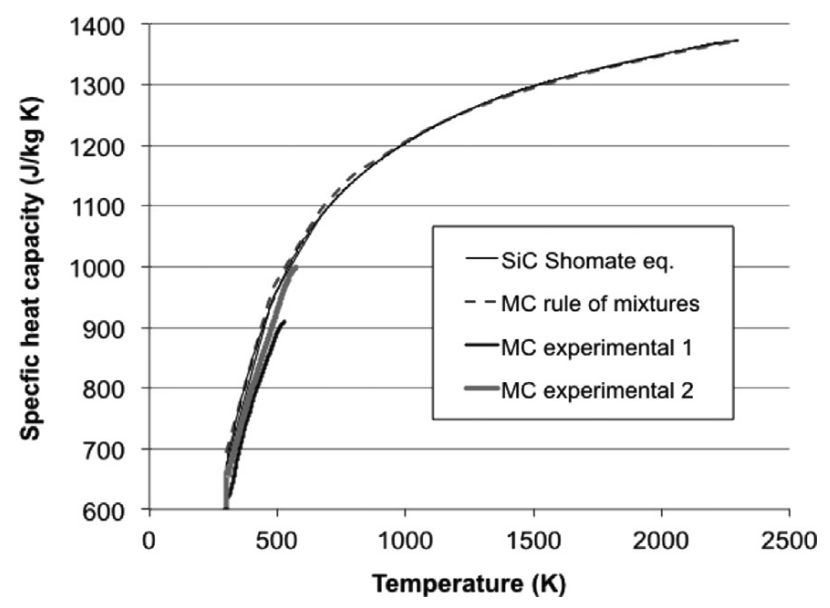

Fig. 3. Specific heat capacity as a function of the temperature for the MC stabilized at $1473 \mathrm{~K}$.

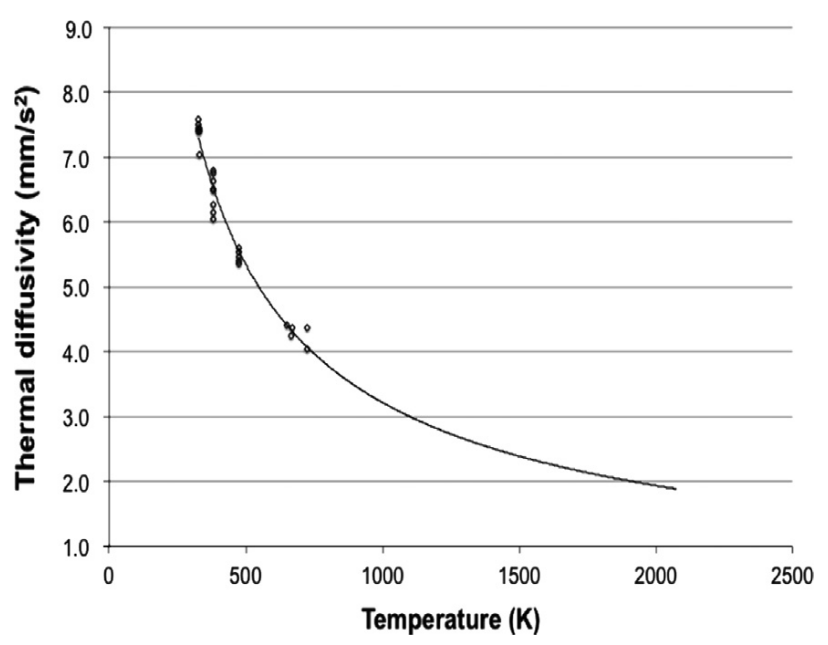

Fig. 4. Thermal diffusivity of MC in function of the temperature.

matrix (darker parts). The porosity of the material is also visible in the black areas at the top of the micrograph.

The high alumina cement, used as binding agent, ensures good mechanical properties to concrete, while $\mathrm{SiC}$ aggregates give its refractoriness [4].

During first stabilisation cycle, cement undergoes several microstructural evolutions: dehydration (293 K-573 K), 
Table 2

Thermal conductivity and thermal diffusivity of high-purity silicon carbide [12].

\begin{tabular}{rll}
\hline Temperature $(\mathrm{K})$ & $\begin{array}{l}\text { Thermal conductivity } \\
(\mathrm{W} / \mathrm{mK})\end{array}$ & $\begin{array}{l}\text { Thermal diffusivity } \\
\left(\mathrm{mm} / \mathrm{s}^{2}\right)^{\mathrm{a}}\end{array}$ \\
\hline 300 & 490 & 227.2 \\
500 & 240 & 77.6 \\
1000 & 110 & 28.4 \\
1200 & 90 & 22.4 \\
\hline
\end{tabular}

a Calculated using a density of $3210 \mathrm{~kg} / \mathrm{m}^{3}$ [12] and a specific heat capacity from SiC Shomate equations [8].

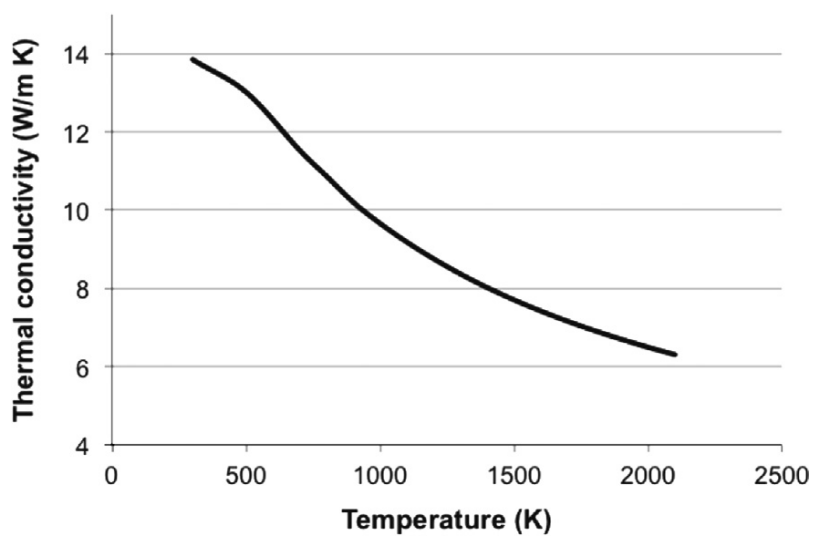

Fig. 5. Thermal conductivity of MC.

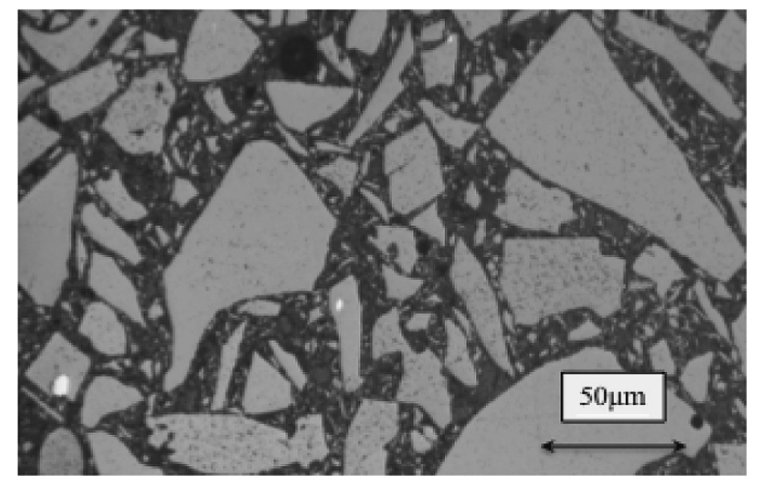

Fig. 6. Microstructure of SiC-based MC, fired at $1473 \mathrm{~K}$ during $5 \mathrm{~h}$.

recrystallisation ( $713 \mathrm{~K}-1173 \mathrm{~K}$ ), eutectic liquid phases formation, sintering and densification (1073 K-1773 K) [4], with a change in thermo-mechanical properties. All cement microstructural transformations are known as conversion. Several studies have been made on this topic [6]. Conversion can be divided into three parts: in first conversion (293 K-1073 K), concrete undergoes thermal damage, connected to mismatch of expansion behaviour between cement matrix and aggregates, which results in lower Young's modulus. In this domain the concrete has a damageable elastic behaviour; in transition domain (1073 K-1273 K) concrete ceramization begins, continuing in third conversion ( $1273 \mathrm{~K}-1773 \mathrm{~K}$ ), with a viscoplastic behaviour, driven by the development of eutectic liquid phases. Rupture of the concrete is always quasi-brittle [6].

Thermo-mechanical properties of MC are shown in Table 3: Young's modulus and rupture bending strength increase with stabilisation temperature, due to increasing densification and sintering of concrete at higher stabilisation temperatures.

Bending strength has been measured using a thermomechanical testing machine MTS $50 \mathrm{kN}$ and an AET oven to reach testing temperature ( $1873 \mathrm{~K}$ maximal temperature). Young's modulus values have been obtained by the resonance frequency method [13].

\subsection{Solar furnace facility}

The 2 kW Medium Size Solar Furnace (MSSF) test facility (Fig. 7) is used to characterise MC at very high temperature, measuring mass loss as a function of time and for different concentrated solar fluxes. All tests were done at $84 \mathrm{kPa}$ total air pressure, which is the standard value at PROMES laboratory located at $1500 \mathrm{~m}$ altitude. The calculated oxygen partial pressure is of $19 \mathrm{kPa}$.

The heliostat, a mobile mirror that follows the apparent movement of the sun during the day, reflects sun radiation towards a $2 \mathrm{~m}$ parabolic mirror with a focal length of $851 \mathrm{~mm}$, which concentrates solar power to its focus. A louvered shutter is placed between the heliostat and the parabolic concentrator, in order to control the solar flux level. The sample-holder is water-cooled [14].

The material surface temperature is measured using a blind-solar monochromatic ( $5 \mu \mathrm{m})$ pyrometer, with a focal length of $490 \mathrm{~mm}$ and an analysis spot diameter of $1.7 \mathrm{~mm}$.

The solar flux absorbed $\left(\phi_{a b s}\right)$ by the material is calculated according to the following expression:

$\phi_{a b s}=\alpha_{M} S F E_{S}$

where $\alpha_{M}$ is the solar absorptivity, depending on the material properties, $S$ is the surface exposed to the solar flux, $F$ is a concentration factor, depending on the mirrors, $E_{S}$ is the direct solar flux measured using a pyrheliometer.

Solar absorptivity has been measured by FT-IR technique.

This expression can be rearranged dividing by the surface and merging $F$ and $E_{S}$ :

$q_{a b s}=\alpha_{M} q_{e}$

where $q_{a b s}$ is the absorbed solar flux $\left(\phi_{a b s} / S\right)$ and $q_{e}$ is the concentrated solar flux $\left(F \cdot E_{S}\right)$.

Concentrated solar flux is a Gaussian function, with a maximum value of $15 \mathrm{MW} / \mathrm{m}^{2}$ for a $1000 \mathrm{~W} / \mathrm{m}^{2}$ direct solar flux. The concentration factor is 15,000 for this solar furnace facility.

MC can be heated up to $2180 \mathrm{~K}$, for a concentrated solar flux of $5.9 \mathrm{MW} / \mathrm{m}^{2}$. Above this level, smokes composed of $\mathrm{SiO}$ and $\mathrm{CO}$ gases, $\mathrm{SiO}_{2}$ particles produced by re-condensation, and other volatile particles of aluminium and calcium from cement vaporisation (Fig. 14), are generated and the pyrometer cannot be used anymore. Smokes hinder measurement and could damage the instrument lens. Thermocouples are used to measure temperature values inside our material. Mass loss measurements obtained by weighing - before and after test - are performed with a resolution of $0.1 \mathrm{mg}$. Post-test characterizations of the materials are carried out using SEM and optical microscopy. 
Table 3

Thermo-mechanical properties of MC: Young's modulus at $293 \mathrm{~K}$ and bending strength at $293 \mathrm{~K}, 1373 \mathrm{~K}$ and $1473 \mathrm{~K}$. At $1473 \mathrm{~K}$ tests were performed at two crosshead speeds, to exhibit the visco-plastic effect.

\begin{tabular}{|c|c|c|c|c|c|}
\hline \multirow[t]{2}{*}{ Stabilisation temperature, $\mathrm{K}$} & \multirow[t]{2}{*}{$E$ at $293 \mathrm{~K}(\mathrm{GPa})$} & \multicolumn{3}{|c|}{$\sigma_{\mathrm{R}}(0.2 \mathrm{~mm} / \mathrm{min})(\mathrm{MPa})$} & \multirow{2}{*}{$\frac{\sigma_{\mathrm{R}}(0.02 \mathrm{~mm} / \mathrm{min})(\mathrm{MPa})}{1473 \mathrm{~K}}$} \\
\hline & & $293 \mathrm{~K}$ & $1373 \mathrm{~K}$ & $1473 \mathrm{~K}$ & \\
\hline 973 & 40 & 6 & - & 12 & 10 \\
\hline 1173 & 70 & 14 & 17 & 16 & 13 \\
\hline 1473 & 75 & 27 & 29 & 25 & 18 \\
\hline
\end{tabular}

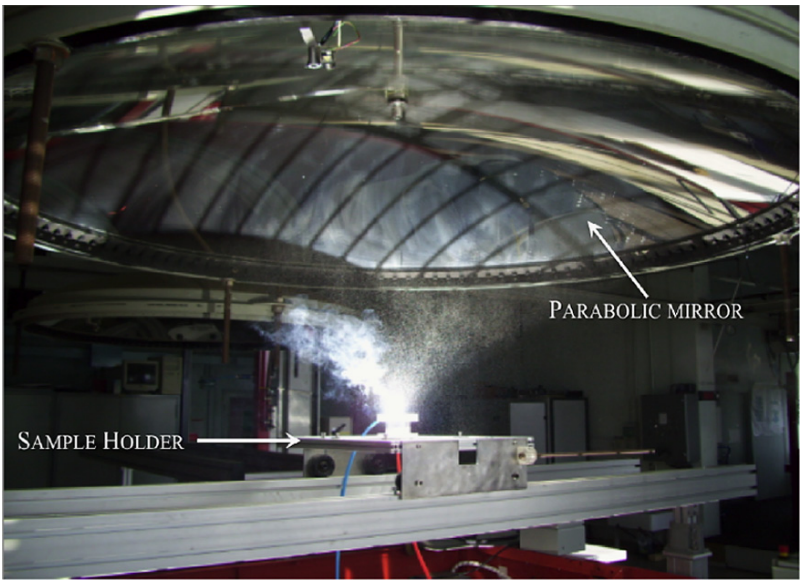

Fig. 7. Solar furnace facility, during a test.

\section{Results and discussion}

\subsection{SiC and concrete active oxidation}

$6 \mathrm{H} \alpha$-SiC samples (from Boostec now Mersen, France) have been tested during $30 \mathrm{~s}$ for different concentrated solar fluxes: Fig. 8 shows samples tested at $7 \mathrm{MW} / \mathrm{m}^{2}$ (a) and $13.5 \mathrm{MW} / \mathrm{m}^{2}$ (b). Samples have been placed on the top of a concrete sample to reach high temperature values and to reproduce similar concrete test conditions. Compared to MC, conductivity of this $6 \mathrm{H} \alpha$-type silicon carbide is 14 times greater at room temperature $(180 \mathrm{~W} / \mathrm{mK}$ vs. $12.8-$ $14.8 \mathrm{~W} / \mathrm{mK})$. To recreate similar temperature conditions and observe the same phenomena, this configuration has been chosen.

First tests showed $\mathrm{SiC}$ active oxidation, with smokes generation and a mass loss of $20.5 \mathrm{mg} / \mathrm{cm}^{2}$. Smokes amount is really limited and passive-to-active transition appears, with $\mathrm{SiO}_{2}$ scale breakdown. Hinze and Graham [2], Turkdogan et al. [15], Heuer and Lou [16], Balat et al. [17-21] have discussed passive-to-active oxidation transition in SiC. Passive oxidation is characterised by the presence of a $\mathrm{SiO}_{2}$ protective scale without bubbles and active oxidation is characterised by the presence of bubbles on the surfaces, and/or silica layer damage $\left(\mathrm{SiO}_{2}\right.$ decomposition and $\mathrm{CO}$ emission) or bare SiC surface according to the oxygen partial pressure and temperature conditions [17-21]. According to literature, for an oxygen partial pressure of $19 \mathrm{kPa}$, passive-to-active transition temperature is expected to be in the range $1940 \mathrm{~K}$ (Gulbransen [22]) - $2130 \mathrm{~K}$ (Hinze and Graham [2]). According to Balat et al. [17] the value expected is of $1990 \mathrm{~K}$. Surface temperature measurements by pyrometer for sintered $\alpha$-SiC are not available to confirm this value. When tested under 11 and $13.5 \mathrm{MW} / \mathrm{m}^{2} \mathrm{SiC}$ samples show $\mathrm{SiO}_{2}$ re-deposition after stopping the solar flux due to the reaction between $\mathrm{SiO}$ smoke and the oxygen of the surrounding atmosphere and the deposit is mainly present in the colder area.

Similar observations can be done on SiC-based concrete. Fig. 9 shows three samples exposed to $13.5 \mathrm{MW} / \mathrm{m}^{2}$ during 7, 30 and $90 \mathrm{~s}$. Crater diameter increases with exposure time. All samples show silica deposition on the outer region, like for sintered $\alpha$-SiC, and liquid phases solidified at the edge of the crater. Central zone after 7 and $30 \mathrm{~s}$ shows condensed liquid phases. Sample tested during $90 \mathrm{~s}$ shows a crater more pronounced in the central zone and a darker edge zone. Heat conduction transfers energy through the thickness towards the water-cooled sampleholder. Another part of this energy is dispersed by convection and surface radiation. Moreover heat conduction allows tangential heat transfer: this is the reason why the crater diameter increases with time.

\subsection{Mass loss in concrete and in pure $\alpha$-SiC}

Different tests have been made on micro-concrete to study its behaviour in active oxidation conditions.

MC has been tested at $8,10,11$ and $13.5 \mathrm{MW} / \mathrm{m}^{2}$ solar flux, during 7, 15, 30, 60 and $90 \mathrm{~s}$. In these conditions, smokes are generated and it is possible to evaluate the mass loss by weighing. Absolute mass loss is divided by the sample surface, measured by caliper.

Fig. 10 shows the results for MC samples and for pure $\alpha$-SiC, that have been tested during $30 \mathrm{~s}$ under three concentrated solar fluxes: 7, 11 and $13.5 \mathrm{MW} / \mathrm{m}^{2}$. For the MC, linear trends interpolate results at different fluxes. The mass loss is increasing with the concentrated solar flux and with time. Pure $\alpha$-SiC shows higher mass loss than $\mathrm{MC}$ at 11 and $13.5 \mathrm{MW} / \mathrm{m}^{2}$ for $30 \mathrm{~s}$ exposure. This observation is really interesting and can be explained by the different manufacturing processes of the two materials. Pure silicon carbide is almost an ideal material, without porosity and impurities. MC has a 17 vol\% porosity and it contains $20.5 \mathrm{wt} \%$ of high alumina cement, which will not undergo active oxidation. Moreover cement eutectic liquid phases are formed since $1613 \mathrm{~K}$. Sintered $\alpha$-SiC has thus a greater surface area exposed to the atmospheric oxygen as compared to $\mathrm{SiC}$ in $\mathrm{MC}$, with a greater mass loss with respect to the latter. 
a

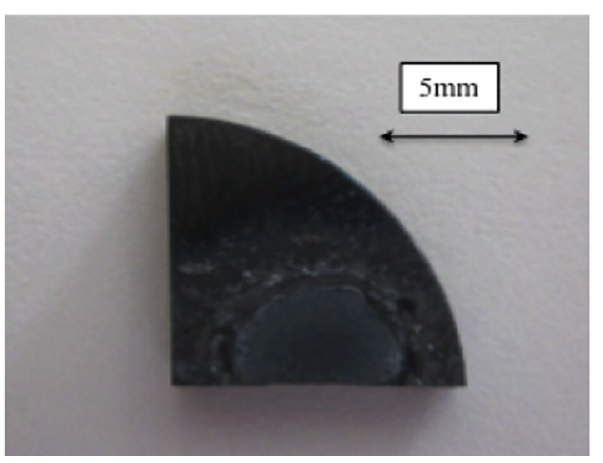

b

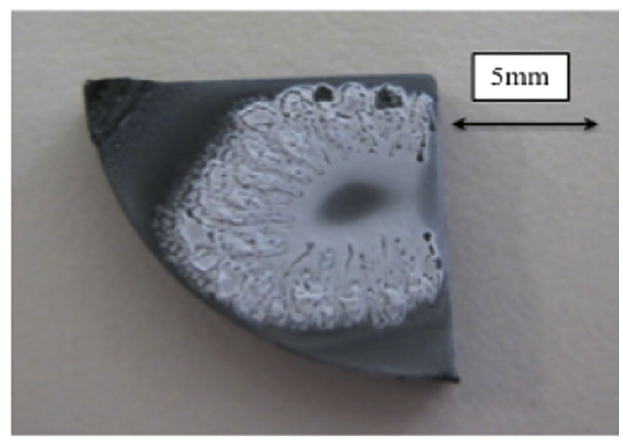

Fig. 8. Sintered $6 \mathrm{H} \alpha-\mathrm{SiC}$ tested at (a) $7 \mathrm{MW} / \mathrm{m}^{2}$ and (b) $13.5 \mathrm{MW} / \mathrm{m}^{2}$ during $30 \mathrm{~s}$.

a

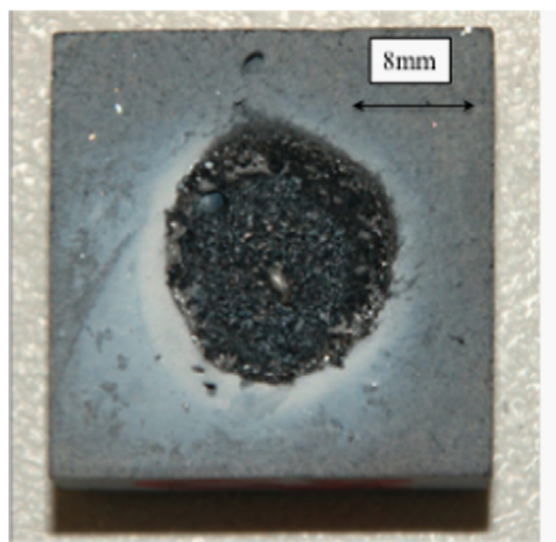

b

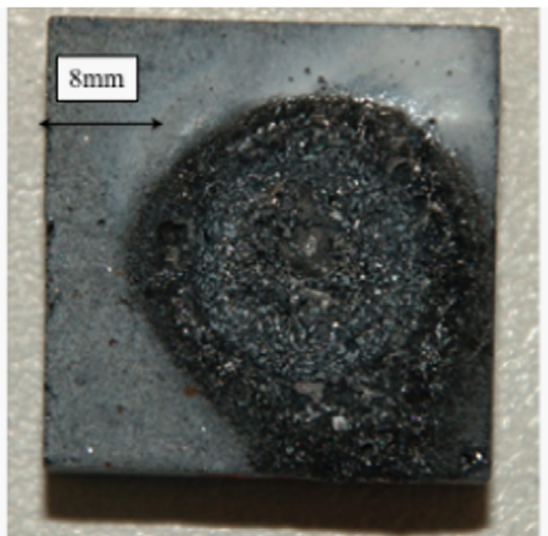

C

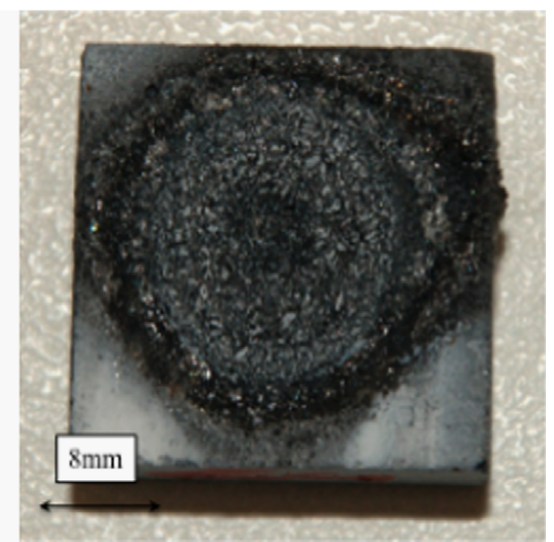

Fig. 9. SiC-based concrete samples tested at $13.5 \mathrm{MW} / \mathrm{m}^{2}$, during $7 \mathrm{~s} \mathrm{(a),} 30 \mathrm{~s}$ (b) and $90 \mathrm{~s}$ (c).

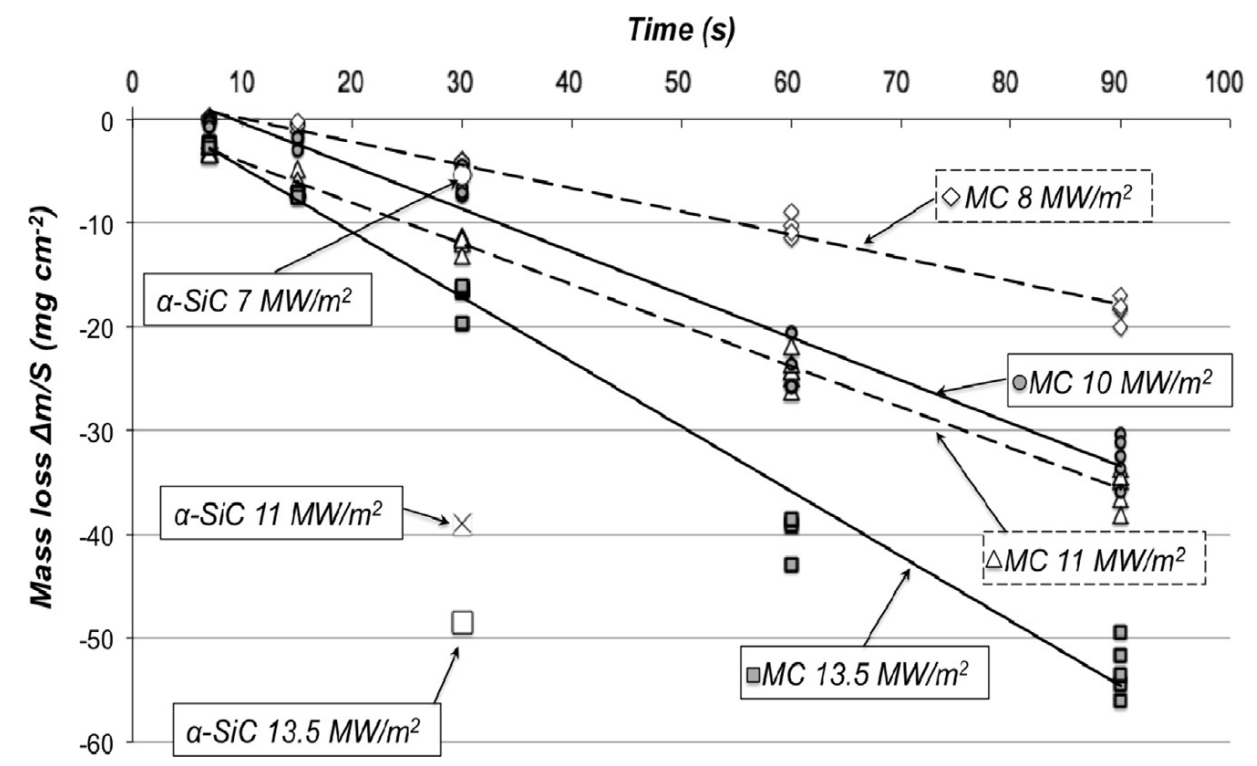

Fig. 10. Mass loss curves for different exposure durations and concentrated solar fluxes for $\alpha-\operatorname{SiC}$ and MC.

The behaviour observed for $\alpha$-SiC and for MC shown in Fig. 10 is clearly an example of silicon carbide active oxidation, with smokes generation and mass consumption.

Linear behaviour is explained by Hinze and Graham [2] and Balat et al. [17-21] that extended to silicon carbide Wagner theory on silicon active oxidation [1]. They studied active oxidation of $\mathrm{SiC}$ exposed to different pressure values, given that active oxidation gives a linear mass loss.

In our active oxidation conditions, surface temperature is not measurable directly, because of smokes generation that prevents the use of pyrometer. For this reason, temperature measurement by the indirect method is under study. 


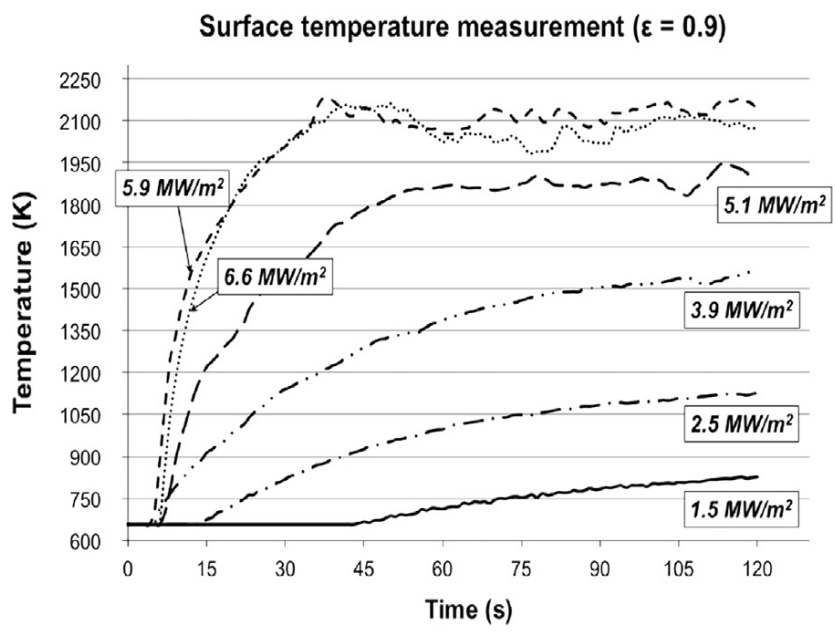

Fig.11. Surface temperature measurement by optical pyrometry for concentrated solar flux from 1.6 to $6.6 \mathrm{MW} / \mathrm{m}^{2}$.

\subsection{Temperature measurements}

Pyrometric measurements have shown an increasing value of the surface temperature with the concentrated solar flux. Experimental measurements were made with the blackbody hypothesis (emissivity=1) set in the Heitronics KT15 pyrometer. Afterwards, temperature values were corrected using Planck's law taking into account a spectral $(5 \mu \mathrm{m})$ normal emissivity for the MC of 0.9 , independent of temperature, which is a likely value for the spectral normal emissivity of $\mathrm{SiC}$ ( $80 \%$ content of the $\mathrm{MC}$ ).

Fig. 11 shows the corrected values of the surface temperature, measured by optical pyrometry. Temperature increases with time up to an asymptotic value after $90 \mathrm{~s}$. Between 1.5 and $5.1 \mathrm{MW} / \mathrm{m}^{2}$ the surface temperature increases regularly. Above $5.1 \mathrm{MW} / \mathrm{m}^{2}$ smokes generation begins and above $5.9 \mathrm{MW} / \mathrm{m}^{2}$ it is not possible to measure the surface temperature anymore due to the intense smokes generation disturbing the measurement of the surface radiance.

For this reason, this optical pyrometer cannot be used for solar fluxes greater than $5.9 \mathrm{MW} / \mathrm{m}^{2}$. Smokes generation also reduces the amount of solar flux reaching the MC surface, thus reducing the surface temperature. Moreover, measurements under $663 \mathrm{~K}$ are not possible because of instrument sensibility and the highest surface temperature measured is of $2180 \mathrm{~K}$ due to smokes limitation and not due to the pyrometer.

According to Fig. 11, passive-to-active transition appears at $2100 \mathrm{~K}$, for an oxygen partial pressure of $19 \mathrm{kPa}$, which is the stability value. These values agree with literature data [17].

A second approach has been tried to measure temperature beyond the transition, which consists of temperature measurements by thermocouples. Different tests have been made on MC at different solar fluxes, immerging thermocouples in depth: type $\mathrm{S}$ thermocouples have been immerged at $3 \mathrm{~mm}$ while type $\mathrm{K}$ thermocouples have been immerged at 6 and $9 \mathrm{~mm}$. Fig. 12 shows results for the $6 \mathrm{~mm}$ depth thermocouple. Equilibrium temperature is reached after 120 s. Curves are plotted for different times: 15, 30, 60 and $90 \mathrm{~s}$. A linear behaviour is observed between the measured temperature and the concentrated solar flux, up to the smoke

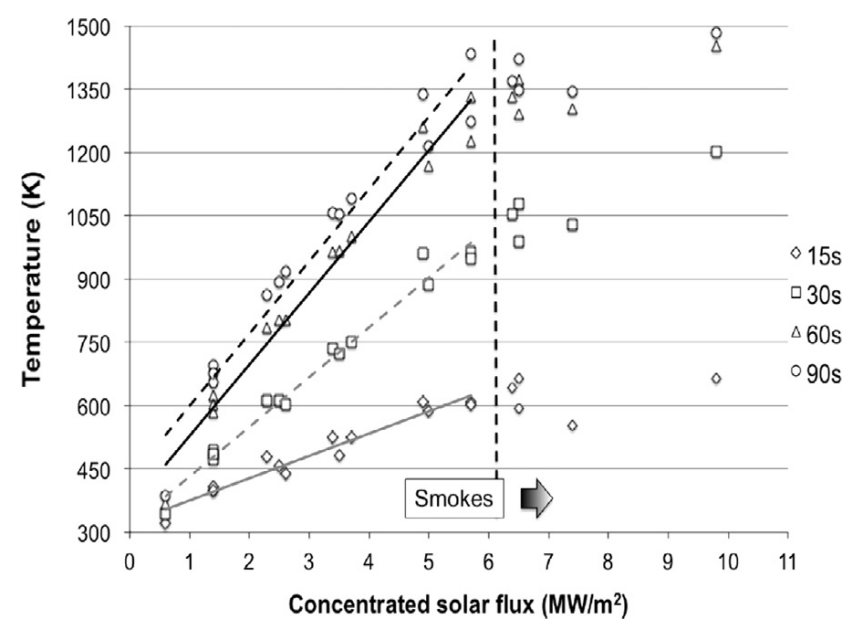

Fig. 12. Temperature measured with thermocouples at $6 \mathrm{~mm}$ from the surface.

generation, i.e. for $5.9 \mathrm{MW} / \mathrm{m}^{2}$ solar flux. All plotted curves have a coefficient of determination $R^{2}$ between 0.95 and 0.98 . In this domain, with a silica-based passive protective layer on the top of the sample, heat conduction is the most important phenomenon, with heat loss by convection and radiation. Increasing concentrated solar flux leads to a linear increase of the temperature inside the sample.

Similar behaviours are observed for the thermocouples located at 3 and $9 \mathrm{~mm}$ : above $5.9 \mathrm{MW} / \mathrm{m}^{2}$, a linear behaviour is not observed anymore. To achieve material modelling, another approach has to be considered.

Thermocouples measurements show a temperature increase after smokes generation, although a data plot is no longer possible.

A thermodynamic approach is under study to understand material behaviour after this limit.

\subsection{Discussion}

SEM and optical microscopy have been used to study ablation concrete behaviour. As an example, a cross section of a sample tested at $8 \mathrm{MW} / \mathrm{m}^{2}$ during $90 \mathrm{~s}$ is shown in Fig. 13. The ablated material can be divided into two zones: the first one is characterised by sublimation, the second one by oxidation. Sublimation of concrete creates craters, more pronounced in the core of the sample. This differential behaviour is due to the Gaussian form of the concentrated solar flux. A second zone is located under this first one and corresponds to oxidised concrete.

Concrete oxidation is caused by oxygen diffusion through cement eutectic liquid phases and concrete porosities. In particular, bubbles are formed at the solid-gas interfaces because of gases formation. Fig. 14 shows EDS analysis of smokes, which were condensed on an alumina bar. Smokes are composed of $\mathrm{SiO}, \mathrm{CO}$ and other gaseous species of alumina and calcium, which are generated from the cement matrix vaporisation.

Fig. 15 shows the MC surface exposed to $13.5 \mathrm{MW} / \mathrm{m}^{2}$ during $90 \mathrm{~s}$. In the central zone, effects of active oxidation on $\mathrm{SiC}$ aggregates are visible (porous surface), while on the edges region, eutectic liquid phases cover the concrete surface. 


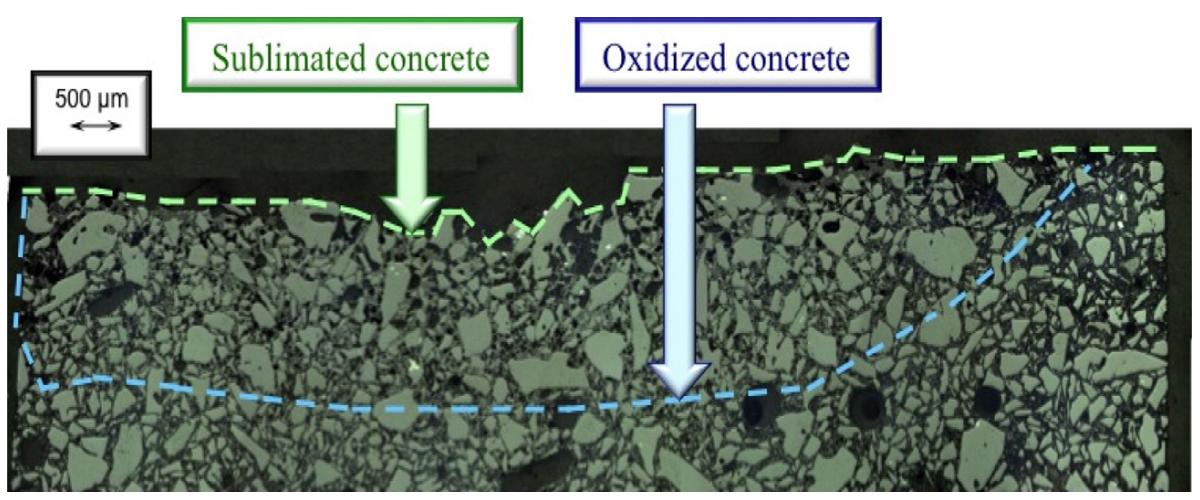

Fig. 13. Optical microscopy view of a MC polished specimen exposed to $8 \mathrm{MW} / \mathrm{m}^{2}$ during $90 \mathrm{~s}$ (cross section).

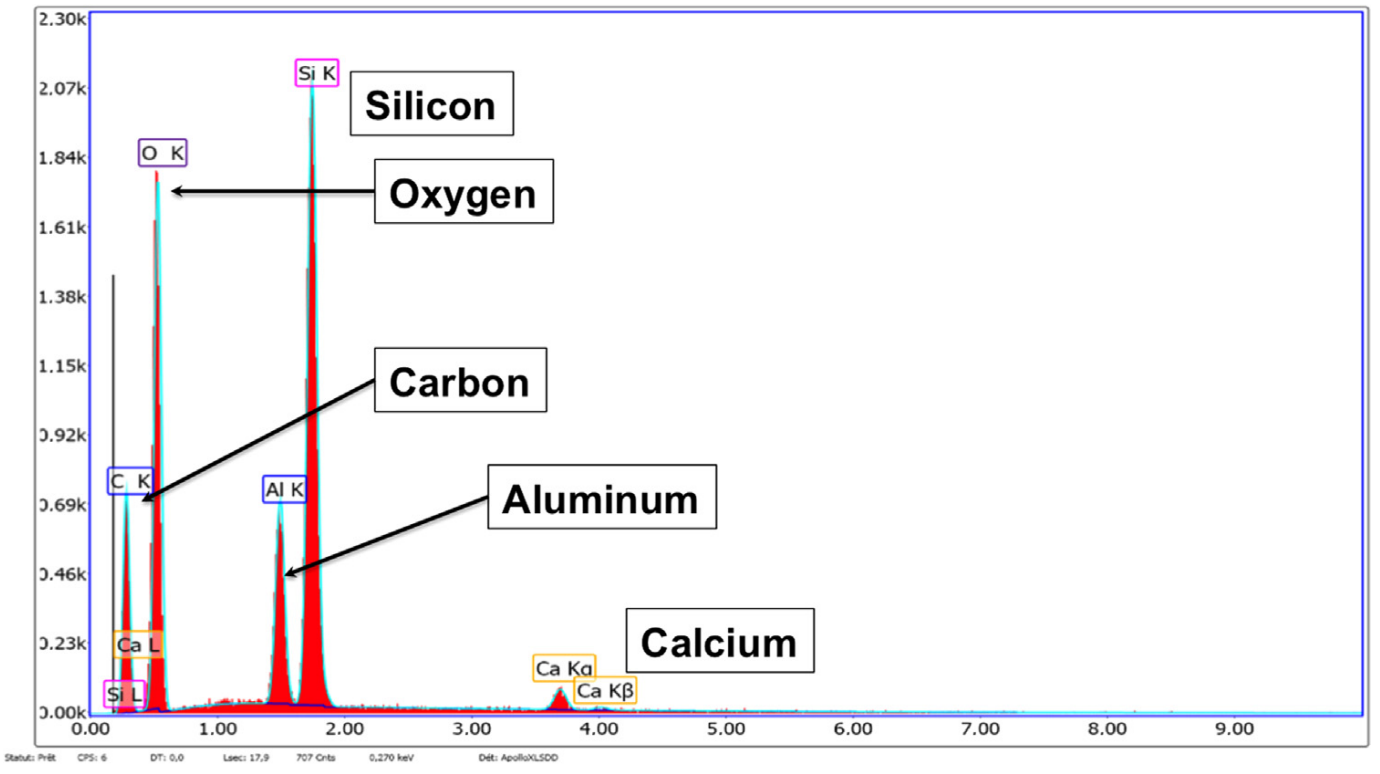

Fig. 14. EDS analysis of the smoke condensate generated after active oxidation of MC.

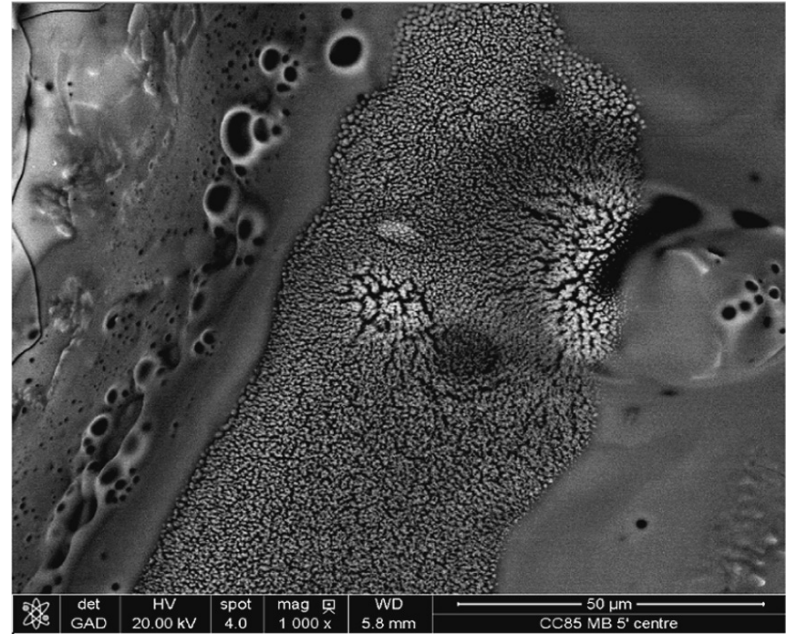

Fig. 15. SEM image of MC exposed during $90 \mathrm{~s}$ to $13.5 \mathrm{MW} / \mathrm{m}^{2}$.

Micro-cracks formed during concrete cooling are visible on the left of Fig. 15. A mismatch of thermal expansion coefficient between glass phases, cement matrix and $\mathrm{SiC}$ aggregates is the cause of this phenomenon, which is evident during sample cooling after test. Bubbles are visible in cement liquid phase. Evaporation of gases,

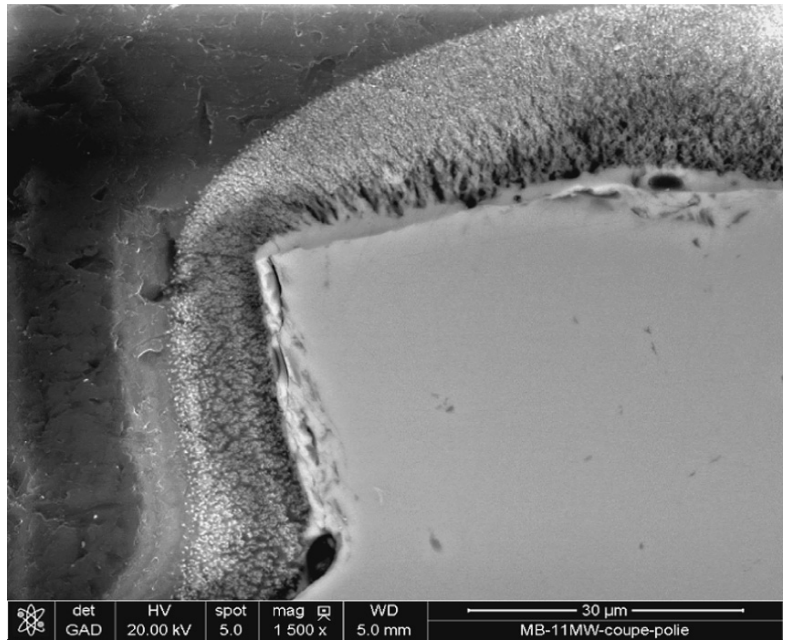

Fig. 16. SEM image of MC (cross section): SiC aggregate after active oxidation at $10 \mathrm{MW} / \mathrm{m}^{2}$ during $90 \mathrm{~s}$.

formed during concrete high temperature transformations, is probably the cause of this phenomenon.

$\mathrm{SiC}$ aggregate after active oxidation at $10 \mathrm{MW} / \mathrm{m}^{2}$ during $90 \mathrm{~s}$ is shown in Fig. 16. A liquid phase can be observed between the $\mathrm{SiC}$ aggregate and the vaporisation zone. This 


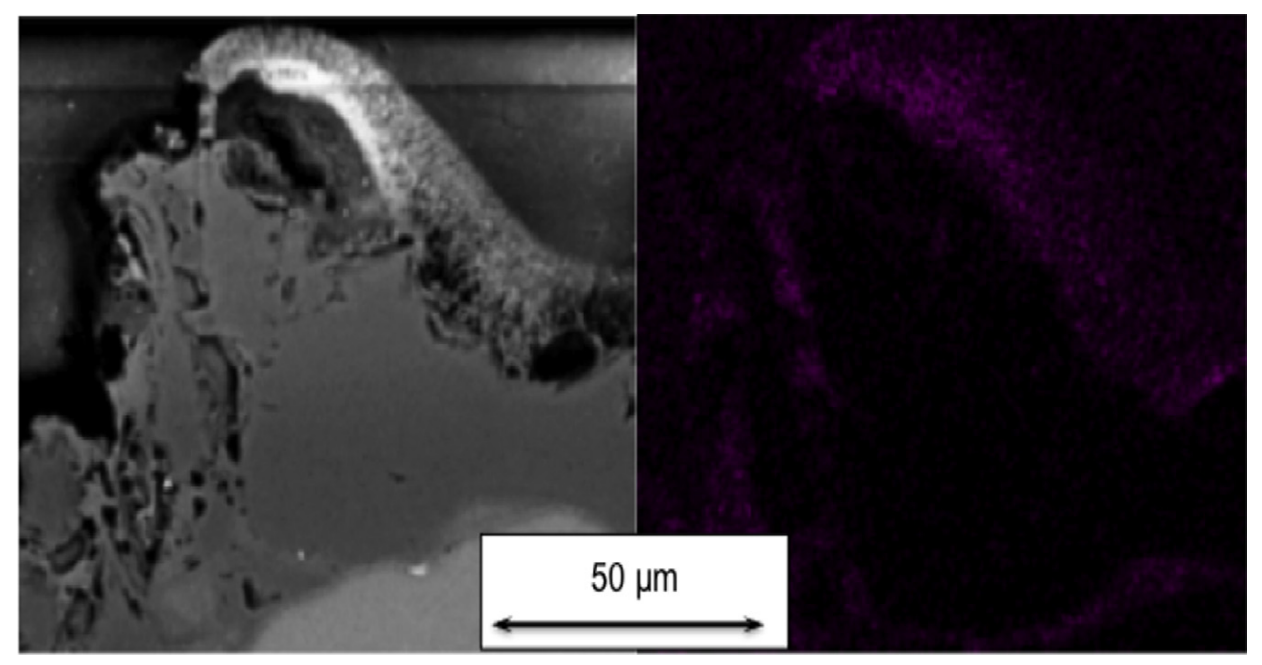

Fig. 17. SEM image (left) and EDS cartography for oxygen (right) of SiC aggregate after active oxidation at $11 \mathrm{MW} / \mathrm{m}^{2}$ for $90 \mathrm{~s}$.

liquid phase could come from cement eutectics or liquid silicon, formed at $1960 \mathrm{~K}$ from solid SiC [23].

Another cross section of MC sample is shown in Fig. 17. Active oxidation is observed on the top of a SiC aggregate: the points in the image on the right represent oxygen, detected using EDS analysis. Oxygen cannot penetrate SiC aggregate: they attack aggregates surface, producing $\mathrm{SiO}$ gases.

Oxygen detected in depth of the material is bonded with aluminium, calcium and silicon from cement matrix. Oxygen could pass through porosities and cement phase between the aggregates, but it is not possible to observe it.

\section{Conclusions/prospects}

MC oxidation has been studied using solar furnace facility, with concentrated solar fluxes up to $13.5 \mathrm{MW} / \mathrm{m}^{2}$. The evolution of the mass loss is linear with time. This is the result of active oxidation of the $\mathrm{SiC}$ aggregates, already studied by Balat et al. [14], [17-21], [24-26]. For concentrated solar flux higher than $5.9 \mathrm{MW} / \mathrm{m}^{2}$, smokes generation occurs. Moreover $\mathrm{SiO}_{2}$ is formed by re-condensation of $\mathrm{SiO}$ produced during active oxidation. This smoke prevents direct temperature measurement by optical pyrometry.

Pure silicon carbide has been oxidised at 7, 11 and 13.5 MW/ $/ \mathrm{m}^{2}$ during $30 \mathrm{~s}$. Silica deposition has been observed for solar flux higher than $11 \mathrm{MW} / \mathrm{m}^{2}$. Similar behaviour for MC has been observed. According to experimental results, after $30 \mathrm{~s}$ at 11 and $13.5 \mathrm{MW} / \mathrm{m}^{2}$, mass loss for the MC is greatly smaller than that for pure $\alpha$-type silicon carbide.

This result shows better active oxidation behaviour for $\mathrm{MC}$ with respect to sintered $\alpha-\mathrm{SiC}$, making it very attractive for high oxidising environments.

Furthermore MC has a lower density $\left(2580 \mathrm{~kg} / \mathrm{m}^{3}\right.$ against $3210 \mathrm{~kg} / \mathrm{m}^{3}$ ), which is a critical point in space applications: a decrease of the inert mass allows a higher payload mass, breaking down the costs of the mission. Finally a lower thermal conductivity was found ( $\sim 14 \mathrm{~W} / \mathrm{mK}$ against $180 \mathrm{~W} / \mathrm{mK}$ at $293 \mathrm{~K})$. This is another important advantage of MC as compared to sintered $\alpha-S i C$, because of insulating capabilities and possible applications in thermal shielding in space applications.
According to thermocouple measurements, a linear relation between surface temperature and concentrated solar flux exists. This result could lead to $\mathrm{COMSOL}^{\circledR}$ modelling of heat transfer in the material. Optimisation loop could allow the calculation of the absorbed solar flux, solar absorptivity and surface temperature of the material. Validation will be made with direct measurements by optical pyrometry for concentrated solar flux lower than $5.9 \mathrm{MW} / \mathrm{m}^{2}$. This model could lead to a better comprehension of material behaviour and a comparison with pyrometric measurements. Furthermore this approach allows to trace mass loss curves in function of the surface temperature and to calculate the activation energy of active oxidation of MC, which could be compared with the same value for sintered $\alpha-S i C$. Thermodynamic behaviour of MC is under study with GEMINI code, to understand material behaviour beyond $5.9 \mathrm{MW} / \mathrm{m}^{2}$. After this, MatLab ${ }^{\circledR}$ and Abaqus ${ }^{\circledR}$ ablation modelling will be possible.

Liquid phases, active oxidation and bubbling have been observed in the MC, with mass loss and oxygen diffusion in-depth into the material. Two zones were observed by SEM during ablation: the sublimation zone with direct mass loss, and the oxidation zone, with bubbling and porosity rate increasing.

This preliminary study has shown the behaviour of MC in standard atmosphere, without gas flow exposure. The environment in a HRM, in terms of pressure, flow velocity, oxidising partial pressure and chemical composition, is expected to be different with respect to the solar furnace conditions. For this reason we defined the active oxidation observed in this paper as static, in opposition to the HRM, where we could define a dynamic active oxidation.

According to present results we cannot state if MC could be used in HRM applications.

\section{Acknowledgements}

Authors would like to thank CNES and Midi-Pyrenees region for the financial support to the Ph.D. thesis. Authors also thank Yannick Le Maoult for helpful discussions. 


\section{References}

[1] C. Wagner, Passivity during the oxidation of silicon at elevated temperatures, J. Appl. Phys. vol. 29 (no. 9) (1958) 1295-1297.

[2] J.W. Hinze, H.C. Graham, The active oxidation of $\mathrm{Si}$ and $\mathrm{SiC}$ in the viscous gas-flow regime, J. Electrochem. Soc. vol. 123 (no. 7) (1976) 1066-1073.

[3] P.C. Hewlett, Lea's chemistry of cement and concrete, 4th edition, Elsevier, Ltd., 2001 (ISBN: 978-0-750-66256-7).

[4] W.E. Lee, W. Vieira, S. Zhang, G.K. Ahari, H. Sarpoolaky, C. Parr, Castable refractory concretes, Int. Mater. Rev. vol. 46 (no. 3) (2001) $145-167$.

[5] CALDERYS, “TDS CCmicrobéton." 2011.

[6] A. Mazzoni, T. Cutard, Comportement thermomécanique d'un béton réfractaire: effets du renforcement par des fibres minérales, Université Paul Sabatier, Toulouse/Albi, 2009.

[7] "NF P-94-410-3 Essais pour déterminer les propriétés physiques des roches," AFNOR, 2001.

[8] NIST, "Silicon carbide - Condensed phase thermochemistry data." [Online]. Available: 〈http://webbook.nist.gov/cgi/cbook.cgi?ID=C409212 \&Units=CAL\&Mask $=2\rangle$.

[9] NIST, "Quartz - Condensed phase thermochemistry data." [Online]. Available: 〈http://webbook.nist.gov/cgi/cbook.cgi?ID=C14808607\& Mask=2خ.

[10] NIST, "Calcium oxide - Condensed phase thermochemistry data." [Online]. Available: 〈http://webbook.nist.gov/cgi/cbook.cgi?ID=C130 $5788 \&$ Mask $=2\rangle$.

[11] NIST, "Aluminium oxide - Condensed phase thermochemistry data." [Online]. Available: 〈http://webbook.nist.gov/cgi/cbook.cgi?ID=C13 44281\&Mask=2>.

[12] G.A. Slack, Thermal conductivity of pure and impure silicon, silicon carbide, and diamond, J. Appl. Phys. vol. 35 (no. 12) (1964) 3460 3466.

[13] ASTM, Ed., Standard test method for dynamic Young's Modulus, shear modulus, and Poisson's ratio by impulse excitation of vibration, ASTM E1876-09, 2009.

[14] L. Charpentier, K. Dawi, J. Eck, B. Pierrat, J.-L. Sans, M. Balat-Pichelin, Concentrated solar energy to study high temperature materials for space and energy, J. sol. Energy Eng. vol. 133 (2011).

[15] E.T. Turkdogan, P. Grieveson, L.S. Darken, Enhancement of diffusionlimited rates of vaporisation of metals, J. Phys. Chem. vol. 67 (no. 8) (1963) 1647-1654.
[16] A.H. Heuer, V.L.K. Lou, Volatility diagrams for silica, silicon nitride, and silicon carbide and their application to high-temperature decomposition and oxidation, J. Am. Ceram. Soc. vol. 73 (no. 10) (1990) 2789-2803.

[17] M. Balat, G. Flamant, G. Male, G. Pichelin, Active to passive transition in the oxidation of silicon carbide at high temperature and low pressure in molecular and atomic oxygen In the gaseous phase, J. Mater. Sci. vol. 27 (1992) 697-703.

[18] M. Balat, Determination of the active-to-passive transition in the oxidation of silicon carbide in standard and microwave-excited air, J. Eur. Ceram. Soc. vol. 16 (1996) 55-62.

[19] L. Charpentier, M. Balat-Pichelin, F. Audubert, "High temperature oxidation of SiC under helium with low-pressure oxygen - Part 1: Sintered alfa-SiC,", J. Eur. Ceram. Soc. vol. 30 (2010) 2653-2660.

[20] L. Charpentier, M. Balat-Pichelin, H. Glénat, E. Bêche, E. Laborde, F. Audubert, High temperature oxidation of SiC under helium with low-pressure oxygen. Part 2: CVD beta-SiC, J. Eur. Ceram. Soc. vol. 30 (2010) 2661-2670.

[21] K. Dawi, M. Balat-Pichelin, L. Charpentier, F. Audubert, High temperature oxidation of $\mathrm{SiC}$ under helium with low-pressure oxygen. Part 3: beta-SiC-SiC/PyC/SiC, J. Eur. Ceram. Soc. vol. 32 (2012) 485-494.

[22] E.A. Gulbransen, S.A. Jansson, The high-temperature oxidation, reduction, and volatilization reactions of silicon and silicon carbide, Oxid. Metals vol. 4 (no. 3) (1972) 181-201.

[23] M. Jansen, High Performance Non-oxide Ceramics I, Springer, 2002 (ISBN: 978-3-540-43131-2).

[24] M. Balat, R. Berjoan, Oxidation of sintered silicon carbide under microwave-induced $\mathrm{CO}_{2}$ plasma at high temperature: active passive transition, Appl. Surface Sci. vol. 161 (2000) 434-442.

[25] M. Balat, Determination of the active-to-passive transition in the oxidation of silicon carbide in standard and microwave-excited air, J. Eur. Ceram. Soc. vol. 16 (1995) 55-62.

[26] M. Balat, R. Berjoan, G. Pichelin, D. Rochman, High-temperature oxidation of sintered silicon carbide under pure $\mathrm{CO} 2$ at low pressure: active-passive transition, Appl. Surface Sci. vol. 133 (1998) 115-123.

[27] Arianespace, “VEGA User's Manual," 2006. [Online]. Available: 〈http:// www.arianespace.com/launch-services-vega/Vega-user's-manual.asp 〉. 